\title{
Numerical calculations of the thermal deformations of the rectangular minichannel walls
}

\author{
Magdalena Piasecka ${ }^{1, a}$, Sławomir Błasiak ${ }^{1}$ and Tomasz Musiał ${ }^{1}$ \\ ${ }^{1}$ Kielce University of Technology, Faculty of Mechatronics and Mechanical Engineering, Al. 1000-lecia P.P. 7, 25-314 Kielce, Poland
}

\begin{abstract}
This paper analyzes the thermal deformations of the walls of a rectangular minichannel. The distribution of temperature on the walls and the local coefficients of heat transfer between the heated wall and the boiling fluid were determined on the basis of the experimental data. The thermal deformations were examined for two vertical walls: a heated Hastelloy X plate and an unheated stainless steel plate. The heat conduction and displacement equations were solved numerically using Ansys Workbench software. The distributions of temperature and the thermal deformations of the walls were obtained by appropriately combining the software modules with the mathematical description of the physical phenomena occurring in the minichannel and introducing the boundary conditions and the experimental data. It was found that, for the predetermined thermal conditions and the assumed thicknesses of the minichannel walls, thermal deformations can be omitted from further analysis. However, it is important to note that, if the geometrical dimensions of the minichannel had been different, the difference in the temperature along the minichannel length would have resulted in changes in the minichannel shape, i.e. its local narrowing, a reduction in the heat transfer efficiency, and, finally, a local change in the fluid flow rate.
\end{abstract}

\section{Introduction}

An increase in the heat transfer efficiency is achieved by applying appropriate conditions of flow boiling heat transfer. Thermal stress is associated with non-uniform thermal expansion.

In recent years, many works on heat transfer in minichannels have been published. An example of a research paper on the practical application of heat exchangers with a minichannel is [1]; it discusses the usefulness of minichannels in the cooling of integrated circuits. In [2], the author presents a study of heat transfer for the initial phases of boiling flow in a minichannel for environmentally friendly refrigerants. The analysis and model presented in [3] refer to a boiling refrigerant in a heat exchanger; the heat transfer coefficient was determined for channels with conventional and small diameters. The authors of [4] investigated boiling heat transfer for the counter-current flow of R134a refrigerant.

The world literature on flow boiling heat transfer in minichannels does not provide any information on the thermal stress in minichannel elements. Thermal deformations of different surfaces exposed to elevated temperatures have been discussed in the specialist literature but there is no data on heat exchangers with minichannels. The authors of [5] focused on thermal stresses in a planar solid oxide fuel cell. In [6] researchers presented the influence of thermal stress on the failure of a martensitic stainless steel $(\mathrm{CA}-15 \mathrm{M})$ roll determined numerically. The relationship between the level of thermal stress and the geometry of the pressure vessel was presented in [7]. Reference [8] describes a model of a boiler start-up taking account of thermal stress. In the study presented in [9], thermal stress is analyzed to optimize the heating of a steam pipeline and a T-pipe. Thermal stress observed on the minichannel surfaces may cause changes in the minichannel geometry (a reduction in the width and volume), which may influence the heat transfer and flow conditions.

\section{Main aim}

This paper analyzes the thermal stress and deformations accompanying flow boiling heat transfer in a rectangular minichannel of a heat exchanger. The investigations involved determining thermal deformations of two metal walls: a heated Hastelloy X plate and an unheated stainless steel plate. The elements were mounted between two fixed supports. The thermal deformations and the distributions of temperature were determined using the Ansys Workbench software. The experimental part of the study required using infrared thermography. These results were used in numerical calculations to determine the temperature distribution on the minichannel walls and the

\footnotetext{
${ }^{\mathrm{a}}$ Corresponding author: tmpmj@tu.kielce.pl
} 
local coefficients of heat transfer between the heated wall and the boiling fluid in the minichannel.

\section{Experimental issues}

The most important part of the experimental stand was the test module with a vertically-oriented rectangular minichannel of the following dimensions: $1.6 \mathrm{~mm}$ (depth), $16 \mathrm{~mm}$ (width), and $180 \mathrm{~mm}$ (length). The schematic diagram of the test module is shown in fig. 1. The heated wall, which ensured the flow of FC-72 in the minichannel (1), was a metal plate made of Hastelloy X (2) with a thickness of about $0.6 \mathrm{~mm}$. The temperature was measured in the central, axially symmetric, part of the channel using infrared thermography. The channel was insulated on both sides with micanit to prevent the heated wall from deforming. The other wall of the minichannel was a stainless steel plate (3) with a thickness of $5.6 \mathrm{~mm}$. The temperature of both minichannel walls was monitored using a FLIR SC640 infrared camera. The temperature distributions on the outer sides of the minichannel were also registered. Images obtained from the infrared camera were used to produce IRT thermograms (see fig. 3). Before each experimental series, the two metal plates were coated with the black paint (7) to achieve an emissivity of 0.83 [10]. In two consecutive experiments conducted at similar thermal and flow parameters, each minichannel surface was observed with an infrared camera. K-type thermocouples and pressure converters (6) were installed at the minichannel inlet and outlet.

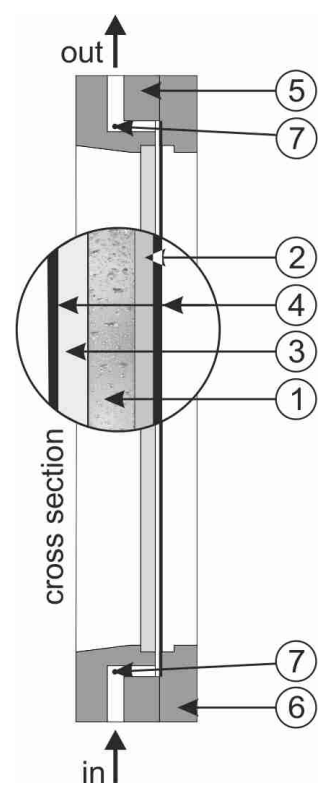

Figure 1. The schematic diagram of the test module: 1-minichannel, 2-the heated Hastelloy X plate, 3-the unheated stainless steel plate, 4-black paint layer, 5-channel body, 6-front cover, 7-thermocouple.

The experimental data was collected using: a data acquisition station, a computer and appropriate software. The supply and control system contained: an inverter welder, a shunt, an ammeter and a voltmeter. The experimental stand is discussed in detail in [11-13].

The thermal deformations of the minichannel surfaces were determined using the experimental data, which included local temperatures of the walls and the heat transfer coefficient calculated by means of a onedimensional mathematical model.

The direction of the heat flow in the model was perpendicular to the direction of the fluid flow in the real minichannel (see fig. 2). The onset of nucleate boiling and enhancement of heat transfer in the minichannel were observed at an appropriate setting of the heat flux supplied to the heated surface. The results correspond to steady-state regimes. Details of the mathematical model are presented in $[11,13]$.

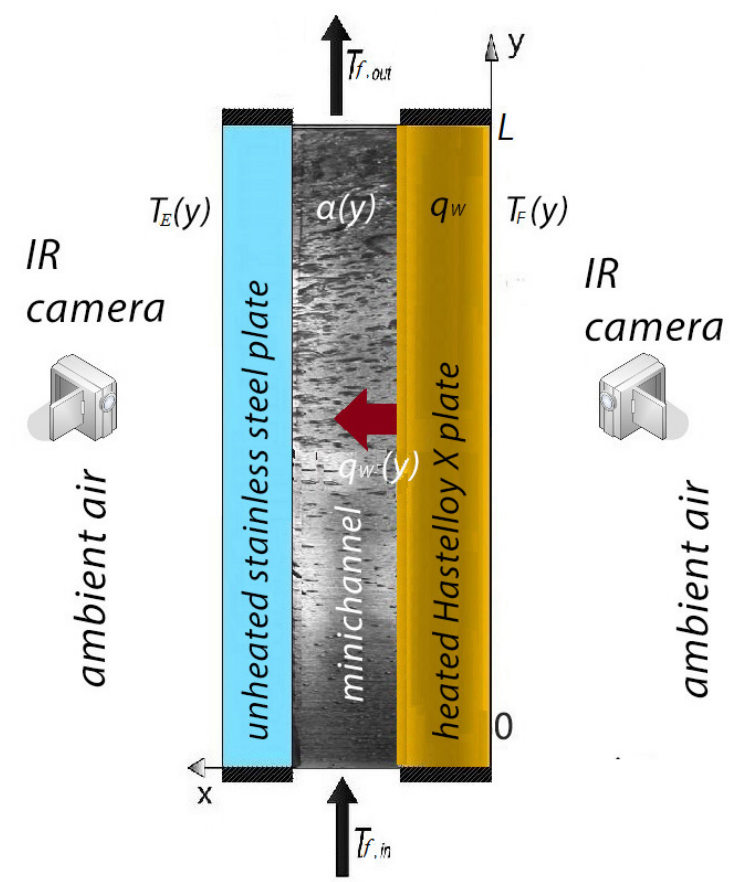

Figure 2. Schematic diagram of the main elements of the test module.

The local values of the heat transfer coefficient $\alpha(y)$ in the area between the fluid and the heated surface of the minichannel were determined using the Robin boundary condition (third-kind boundary condition) on the basis of the known local fluid temperature and the distribution of temperature on the heated plate measured by means of infrared thermography, according to the following equation [13]:

$$
\left.\alpha(y)=q_{w} / T_{F}(y)-T_{f}(y)\right]
$$

where $q_{w}$ - heat flux density transferred to the fluid in the minichannel, $T_{F}(y)$ - local surface temperature measured by infrared thermography, $T_{f}(y)$ - local bulk liquid temperature determined on the basis of the linear distribution of temperature along the length of the channel from the inlet $\left(T_{f, \text { in }}\right)$ to the outlet $\left(T_{f, \text { out }}\right)$, $y$ - distance from the minichannel inlet.

The results were analyzed for two settings - higher and lower values of the heat flux - supplied to the heated plate. The thermograms of the temperature distribution on 
the heated and unheated plates obtained at two different heat fluxes are presented in fig. 3 .
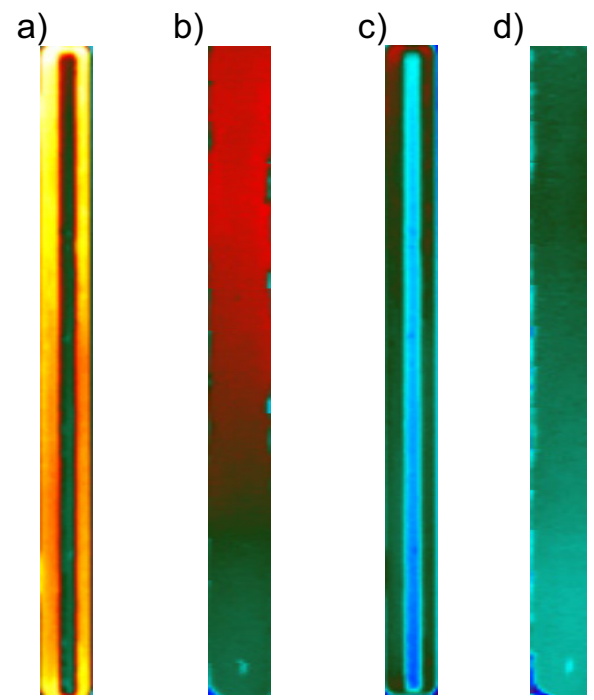

Figure 3. Thermograms of the temperature distribution on: $(\mathrm{a}, \mathrm{c})$ the heated plate, $(b, d)$ the unheated plate, for the higher values of the heat flux $(a, b)$ and the lower values of the heat flux $(c, d)$.

\section{Numerical calculations}

The numerical calculations were performed using Ansys Workbench Academic Research software based on the Finite Element Method (FEM). The channel geometry with its main elements, i.e. the $0.6 \mathrm{~mm}$ thick heated plate and the $5.6 \mathrm{~mm}$ thick stainless steel unheated plate, was modelled using the assumptions presented in fig. 5 .

Temperature difference is known to be the source of stress and strain generation. The temperature field and the stress field are difficult to determine in the steady state. Because of the model complexity, the problem is solved numerically. The calculation process is divided into two steps.

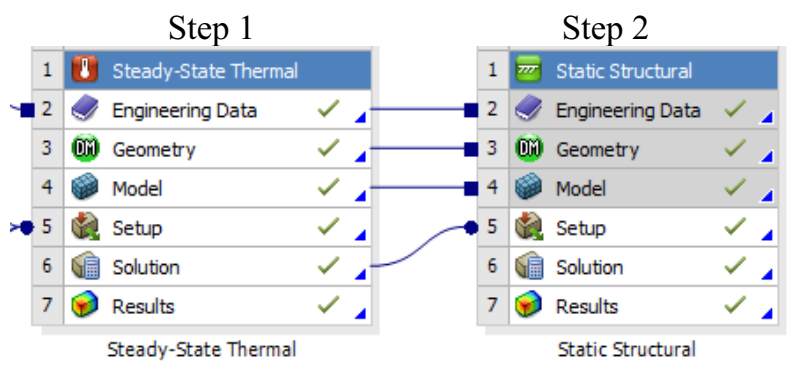

Figure 4. Block connection in Ansys Workbench.

In the first step, the distributions of temperature in the minichannel are determined using the first-kind boundary conditions (the Dirichlet conditions).

In the second step, the problem of elasticity is solved. If the solution is coupled two physical problems, it is possible to calculate the stresses and displacements associated with the changes in temperature along the minichannel walls.

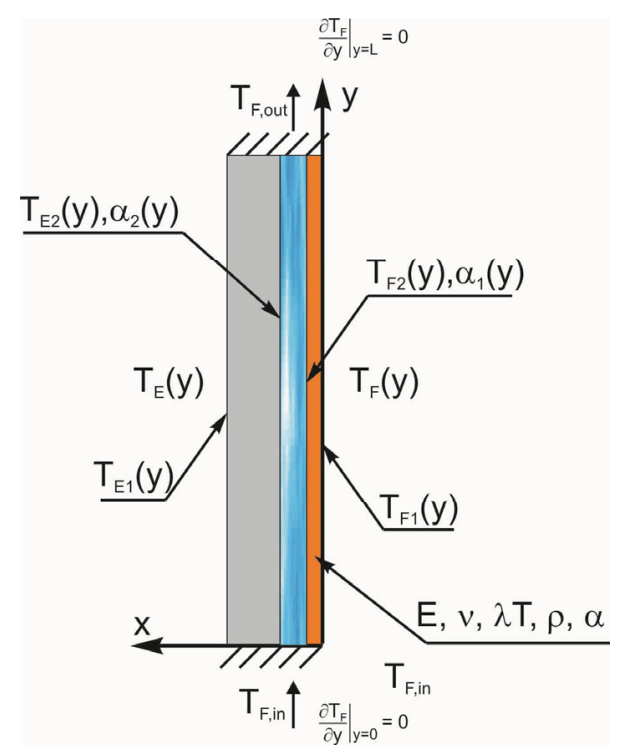

Figure 5. Numerical model assumptions.

The physical phenomena observed during heat transfer in the minichannel for the heated element $[14$, $15]$ and the unheated element can be described by means of the two-dimensional Laplace equation in the following form:

$$
\frac{\partial^{2} \tau_{k}}{\partial x^{2}}+\frac{\partial^{2} \tau_{k}}{\partial y^{2}}=0 \text { where } k=F, E
$$

where: $x$ - direction coinciding with the direction of the fluid flow in the minichannel, $y$ - direction perpendicular to the fluid flow direction, with appropriate boundary conditions based on the experimental data.

The effects of the temperature changes on the stress in the elements can be determined using Hooke's law, the general form of which is written as:

$$
\sigma_{i j}=2 \mu \varepsilon_{i j}+(\lambda e-\beta \tau) \delta_{i j},
$$

where $e$ - expansion $e=\varepsilon_{k k}=\varepsilon_{x x}+\varepsilon_{y y}+\varepsilon_{z z}, \lambda$ and $\mu$ the Lame constants, $\beta$ - thermoelastic constant, $\sigma_{i j}$ stress, $\tau$ - temperature distribution, $\delta_{i j}$ - the Kronecker delta, $v$ - Poisson's ratio.

The relationships between the elastic constants and the thermoelastic constant can be described as:

$$
\mu=\frac{E}{2(1+v)} \quad \lambda=\frac{2 v \mu}{1-2 v} \quad \beta=\alpha(3 \lambda+2 \mu),
$$

where $\alpha$ - thermal expansion coefficient, $E$ - Young's modulus.

From the equation of equilibrium of forces $\sigma_{j, j}+F_{i}=0 \quad(i, j=1,2,3) \quad$ and the component of deformations it is possible to determine the displacement equation in index notation:

$$
\mu \nabla^{2} u_{i}+(\lambda+\mu) u_{k, k i}-\beta \tau_{, i}+F_{i}=0 \quad(i=1,2,3),
$$


where $\nabla^{2}=\frac{\partial^{2}}{\partial x^{2}}+\frac{\partial^{2}}{\partial y^{2}}, \quad F_{i}{ }^{-}$unit forces, $\sigma_{i j}{ }^{-}$stress divergence, $u_{i}$ - displacement, $\nabla^{2}$ - the Laplacian.

The general equations, which describe the physical phenomena in the minichannel, are employed in the appropriate Ansys Workbench modules.

\section{Results and discussion}

The numerical analysis was conducted using a calculation grid of the wall cross-sectional area (similarly as i $[4,5]$ ) divided into 114419 and 13200 elements for the heated plate and the unheated stainless steel plate, respectively. Figure 6 shows the mesh employed in the numerical analysis.

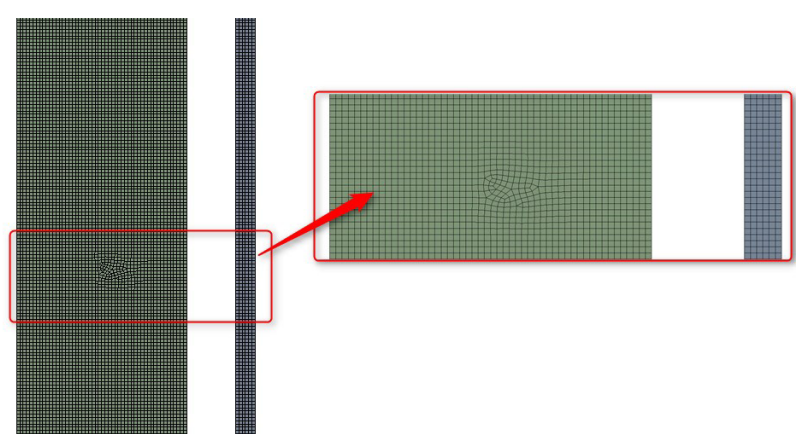

Figure 6. Mesh used in the numerical analysis.

The numerical analysis required assuming the material parameters for the heated Hastelloy X plate and the unheated stainless steel plate, the main elements of the test module. The constants for the materials studied are listed in table 1.

Table 1. Material constants used in the calculations.

\begin{tabular}{|c|c|c|}
\hline & Hastelloy X & Stainless Steel \\
\hline Density, $\rho$ & $8970\left[\mathrm{~kg} / \mathrm{m}^{3}\right]$ & $7750\left[\mathrm{~kg} / \mathrm{m}^{3}\right]$ \\
\hline Poisson's Ratio, $v$ & 0.32 & 0.31 \\
\hline $\begin{array}{c}\text { Thermal } \\
\text { Conductivity, } \lambda T\end{array}$ & $8.9[\mathrm{~W}(/ \mathrm{m} \mathrm{K})]$ & $15.1[\mathrm{~W}(/ \mathrm{m} \mathrm{K})]$ \\
\hline $\begin{array}{c}\text { Young's Modulus, } E \\
\text { Coefficient of } \\
\text { Thermal Expansion, } \\
\alpha\end{array}$ & $2.1110^{11}[\mathrm{~Pa}]$ & $1.9310^{11}[\mathrm{~Pa}]$ \\
\hline \multicolumn{2}{|c|}{$[1 / \mathrm{K}]$} & $1710^{-5}[1 / \mathrm{K}]$ \\
\hline
\end{tabular}

The simulations were based on the experimental data obtained for two heating power settings, where the heat flux supplied to the heated wall was higher or lower.

In one case, the value of the heat flux was $29.1 \mathrm{~kW} / \mathrm{m}^{2}$. Figure 7 shows changes in temperature along the minichannel length, while fig. 8 presents the thermal deformation along the minichannel length. The numbers 1 and 2 refer to the data obtained for the heated and unheated plates, respectively.

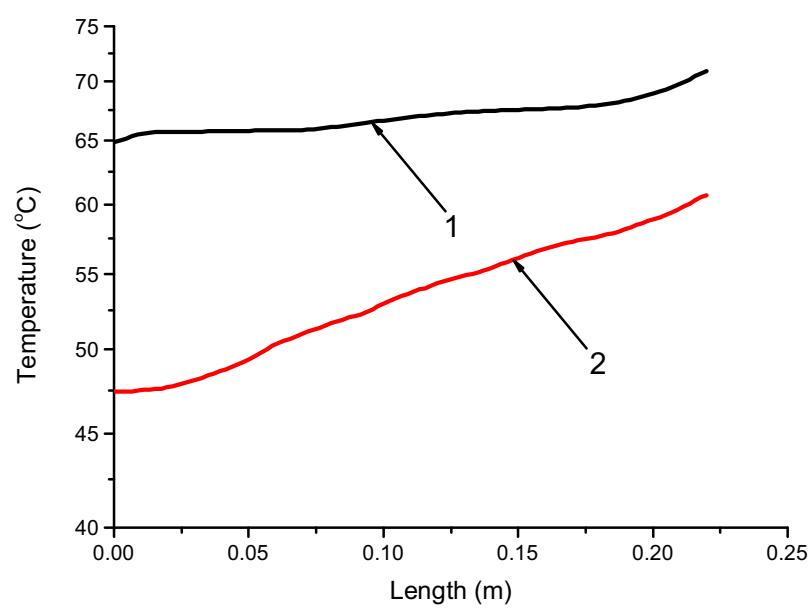

Figure 7. Distribution of temperature along the minichannel length, $q_{\mathrm{w}}=29.1 \mathrm{~kW} / \mathrm{m}^{2}$; data for: 1 ) the heated Hastelloy X plate, 2) the stainless steel plate.

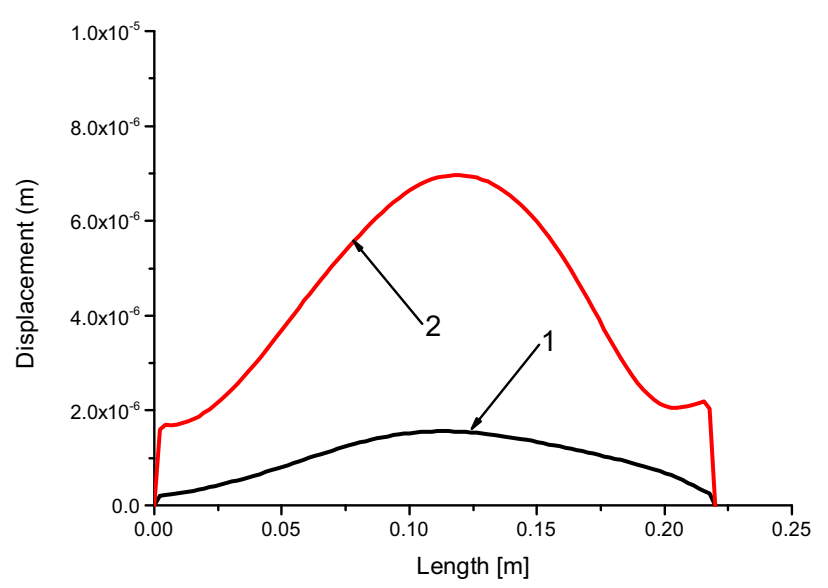

Figure 8. Thermal deformation along the minichannel length, $q_{\mathrm{w}}=29.1 \mathrm{~kW} / \mathrm{m}^{2}$; data for: 1) the heated Hastelloy X plate, 2) the stainless steel plate.

It can be seen that the difference in temperature of the heated element between the inlet and the outlet is approx. $6{ }^{\circ} \mathrm{C}$. In the case of the other surface, the difference in temperature in the minichannel between the ends is much higher, i.e. approx. $15{ }^{\circ} \mathrm{C}$. The non-uniform temperature distributions generate thermal stress leading to changes in the minichannel geometry. As can be seen from fig. 8, the resulting deformations of the major elements are approx. 1-7 $10^{-6} \mathrm{~m}$ and they are the highest in the central part of the minichannel length.

In the other case, the heat flux was $14.5 \mathrm{~kW} / \mathrm{m}^{2}$. The graphs in fig. 9 show that the differences in temperature between the analyzed surfaces did not exceed $5{ }^{\circ} \mathrm{C}$ and at a distance of two-thirds of the length from the inlet, the temperatures were almost equal. 


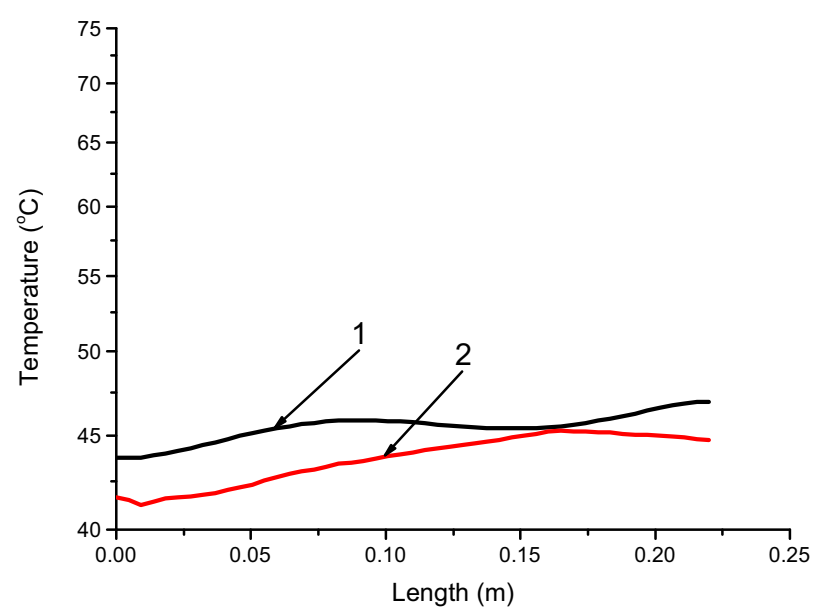

Figure 9. Distribution of temperature along the minichannel length $q_{\mathrm{w}}=14.5 \mathrm{~kW} / \mathrm{m}^{2}$; data for: 1 ) the heated Hastelloy X plate, 2) the stainless steel plate.

The small differences in temperature were responsible for the deformations of the test elements (fig. 10). The deformations recorded for the stainless steel plate and the heated element made of Hastelloy X were below $110^{-6} \mathrm{~m}$ and above $210^{-6} \mathrm{~m}$, respectively.

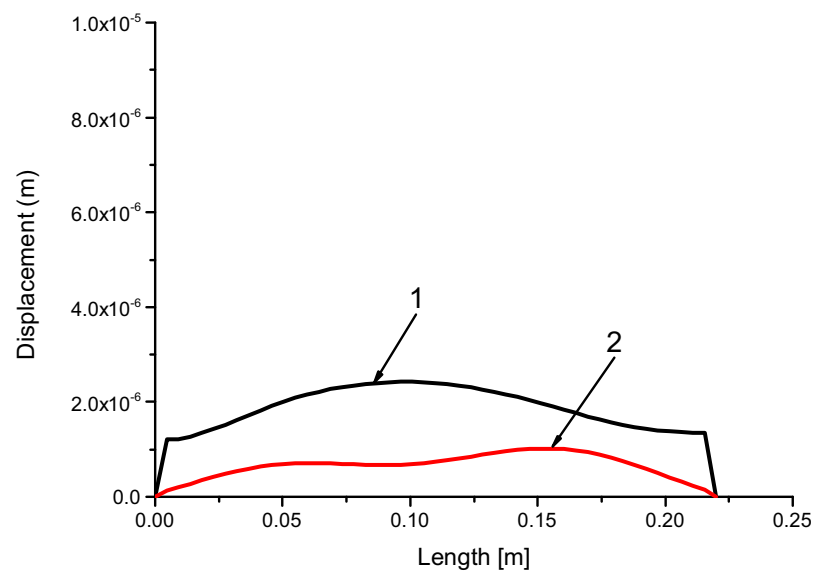

Figure 10. Thermal deformations along the minichannel length $q_{\mathrm{w}}=14.5 \mathrm{~kW} / \mathrm{m}^{2}$; data for: 1) the heated Hastelloy X plate, 2) the stainless steel plate.

From the analysis of the numerical data concerning the thermal deformations in the minichannel it is clear that they did not exceed $0.0001 \mathrm{~m}$. Their values were about three orders of magnitude smaller than the minichannel width, which, practically, had no direct impact on the refrigerant flow.

The problem of thermoelasticity was solved assuming that the heated body affected by thermal deformations and changes in temperature.In the calculations, it was assumed that the material was isotropic and that the temperature change accompanying the deformation was small, so a rise in temperature did not cause a significant change in the elastic and thermal properties of the material.

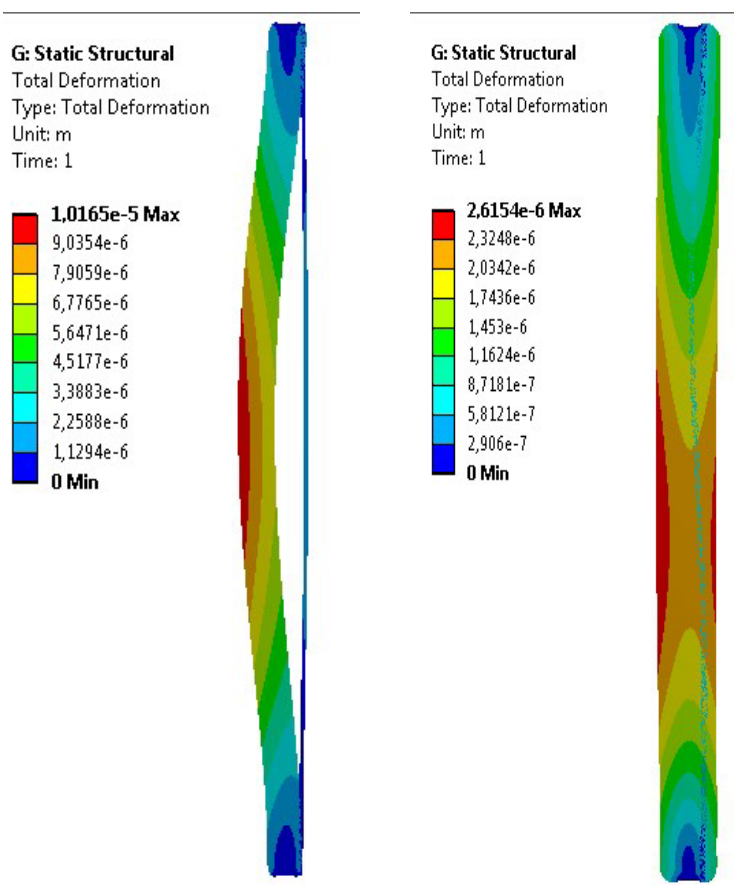

Figure 11. Thermal deformations of the minichannel walls; data for: a) $q_{\mathrm{w}}=14.5 \mathrm{~kW} / \mathrm{m}^{2}$, b) $q_{\mathrm{w}}=14.5 \mathrm{~kW} / \mathrm{m}^{2}$.

Figure 11 shows the thermal deformations of the minichannel walls in their cross-sections for two settings of the heat flux density. The results clearly indicate that, when the heat flux density was higher, the difference in temperature distribution was greater, which caused greater buckling. The thermal deformation was more than $110^{-5} \mathrm{~m}$ at a distance of half of the minichannel length. However, when the heat flux density was lower, expansion of the stainless steel element was observed along the $\mathrm{OX}$ axis. This deformation was not as large as in the other case; the maximum deformation was $210^{-6} \mathrm{~m}$.

The major aim of the simulations was to establish whether the minichannel surfaces undergo deformations in the predetermined temperature range. It was locally change its cross-sectional area and, consequently, lead to any distortions of the fluid flow in the minichannel.

The final finding is that for the predetermined thermal conditions and the assumed thicknesses of the minichannel walls, the deformations can be omitted from further analysis.

\section{Conclusions}

The paper has discussed a numerical analysis of the thermal deformations of rectangular minichannel walls. The distribution of temperature on the minichannel walls and the local heat transfer coefficients were determined on the basis of the experimental results. The numerical calculations were performed to study the thermal deformations of two minichannel walls: the heated Hastelloy X plate and the stainless steel plate. The heat conduction and displacement equations were solved numerically using Ansys Workbench software. The analysis involved appropriately combining the modules 
with the mathematical description of the physical phenomena occurring in the minichannel, introducing the boundary conditions and the experimental data, and calculating the distributions of temperature and the thermal deformations of the walls. The results were represented graphically as a printout of Ansys analysis.

Thermoelastic deformations of the minichannel walls should be one of the most important aspects to be taken into consideration in the modelling of the physical phenomena occurring in this minichannel. The difference in temperature of the heated wall can result in changes in the minichannel shape, with its local narrowing. Moreover, the thermal deformations of the heated wall, which was relatively thick, were not greater than $0.0001 \mathrm{~m}$; they were three orders of magnitude smaller than the minichannel depth and, practically, had no direct impact on the fluid flow.

\section{Acknowledgements}

The research presented here was supported by the National Scientific Center under grant No. DEC2013/09/B/ST8/02825.

\section{References}

1. L. A. Campbell, S. G. Kandlikar, Proc. 2d Int. Conf. Microchannels and Minichannels, Rochester (2004)

2. T. Bohdal, Annual Set The Env. Protection, (in Polish)

2, 262-279 (2000)

3. D. Mikielewicz, J. Mikielewicz, J. Tesmar, Int. J. Heat Mass Tran. 50, 3949-3956 (2007)

4. J. Kaew-On, K. Sakamatapan, S. Wongwises, Exp. Therm. Fluid 35, 364-374 (2011)

5. P. Fan, Y. Zeng, Y. Zhang, G. Li, Int. J. Therm. Sc. 77, 1-10 (2014)

6. E.A. Ariza., A.P. Tschiptschin, C.R.F. Azevedo, Eng. Failure Analysis 48, 78-93 (2015)

7. M. Ahmed, R. Khan, S. Badshah, S. Jan, J. Eng. Adv. Techn. 4, 118-124 (2014)

8. J. Taler, P. Dzierwa, D. Taler, P. Harchut, Energy (2015)

9. J. Taler, D. Taler, S. Lubecki, J. Therm. Stresses 34, 101-1034 (2011)

10. Orzechowski T., Heat transfer on ribs with microstructured surface (in Polish), Kielce Univ. Techn., Kielce, 2003

11. M. Piasecka, Int. J. Heat Mass Tran. 66, 472-488 (2013)

12. M. Piasecka, Heat Tran. Eng. 35 (10), 903-912 (2014)

13. M. Piasecka, B. Maciejewska, K. Strąk, Heat Tran. Eng., to be printed

14. S. Błasiak, Int. J. Heat Mass Tran. 81 90-102 (2015)

15. S. Błasiak, J. E. Takosoglu, P. A. Łaski, J. Therm. Sc. Techn. 9 (2), 1-8 (2014) 